\title{
A Method of Demarcating Critical Failure Impedance Boundary of Multi-Infeed HVDC Systems Based on Minimum Extinction Angle
}

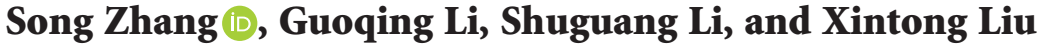 \\ Department of Electrical Engineering, Northeast Electric Power University, Jilin, JL 132012, China \\ Correspondence should be addressed to Song Zhang; zhangsongneepu@aliyun.com
}

Received 7 March 2021; Revised 4 April 2021; Accepted 15 April 2021; Published 1 September 2021

Academic Editor: Bo Yang

Copyright (C) 2021 Song Zhang et al. This is an open access article distributed under the Creative Commons Attribution License, which permits unrestricted use, distribution, and reproduction in any medium, provided the original work is properly cited.

A method of rapidly demarcating the critical commutation failure (CF) region of a multi-infeed high-voltage direct-current (HVDC) system is proposed. Based on the nodal impedance matrix and nodal voltage interaction factor, for different AC fault conditions-both balanced and unbalanced-a method of calculating the extinction angles of converters in multi-infeed HVDC systems is deduced in detail. First, the extinction angles of convertor stations under single-phase, double-phase, and three-phase ground faults and line-to-line faults occurring at any bus in an AC system are calculated. The minimum extinction angle serves as a $\mathrm{CF}$ criterion. If the calculated extinction angle for a certain bus is smaller than the minimum extinction angle, then a fault at that bus will cause CF of the HVDC system and put that bus into a failed bus set. The critical failure impedance boundaries of the topology diagram can therefore be demarcated by examining every bus in the AC system. The validity and accuracy of the proposed index and the method were verified by calculation results based on the three-infeed HVDC system model of the IEEE 39bus system. Finally, the critical failure impedance boundary was demarcated in the IEEE 118-bus system to demonstrate the application in a wider range of systems.

\section{Introduction}

In multi-infeed high-voltage direct-current (HVDC) systems, an AC system failure may cause commutation failure (CF) at the convertor station near a fault location or even CF of the multi-DC transmission lines at the same time or in succession [1-3]. If the commutation function is not recovered quickly, the secure and stable operation of the power grid will be threatened, and a wide-range power outage might occur as a consequence $[4,5]$. However, not all AC system faults can trigger the CF of a DC system [6]. In light of the rapid construction and deployment of DC transmission systems, it is important to establish an accurate, fast scheme for detecting $\mathrm{CF}$ and reducing or avoiding simultaneous CFs in multi-DC transmission systems.

A great deal of research and operational experience have proved that when there is a fault in the AC system, a decrease in the extinction angle of the inverter is the primary cause of $\mathrm{CF}$ of the converter valve group [5, 7-9]. Based on the minimum extinction criteria, the simulation attempts in [10] indicate that a weaker AC system in the receiving grid of a multi-infeed HVDC system aggravates the commutation performance of inverters because of the AC system faults cause a larger voltage magnitude reduction at inverter commutating buses. Son and Kim [11] proposed an improved algorithm that mitigates CF by considering the results of previous studies as well as the control characteristics of HVDC systems. Xiao et al. [12] proposed a weak coupling multi-infeed interaction factor to provide insight into how interinverter interactions influence concurrent $\mathrm{CF}$ behaviors. However, the study of AC systems is not enough. An analytical method based on critical multi-infeed interaction factors was put forward for detecting concurrent CFs quickly.

This work derives a mathematical equation to calculate the extinction angle of the inverter at the moment of an AC system fault by exploring the relationship between the extinction angle and the nodal impedance matrix. Using the critical extinction angle as a criterion, the critical fault impedance boundary of a multi-infeed DC system could be 
identified on the topological graph of a network structure when a three-phase short-circuit ground fault or a singlephase short-circuit ground fault occurs on an AC system. A short-circuit fault at the node lying within the critical fault impedance boundary is more likely to cause CF of a DC system, whereas a fault at the node outside the boundary will not cause CF. The proposed method can quickly identify the critical fault impedance boundary and therefore graphically identify the AC system area where faults can cause CF.

\section{Commutation Failure Mechanism}

The typical six-bridge-arm convector circuit is an example. When commutation between two bridge arms occurs, if the valve simply stops operating, the conduction fails to restore the interdicting ability during a period. Or, if the commutation process fails to complete during the inverse voltage period, conduction occurs again when the voltage added on the valve is positive. These incidents are called CF. The probability of CF on the inverter side is much larger than on the rectifier side, where CF happens only when a trigger circuit has a fault [13]. Therefore, research efforts on detecting CF usually focus on the inverter.

In a multi-infeed $\mathrm{AC} / \mathrm{DC}$ system, an $\mathrm{AC}$ system disturbance is the main cause of CF $[14,15]$. If only AC system faults are considered, a converter bus (CB) voltage drop is the major cause of CF because the extinction angle is smaller than the inherent limit extinction angle of the valve.

The commutation voltage-time area-commutation area for short-is defined as the area surrounded by the line-toline voltage of the converter bus and timer shaft during the commutation period. Figure 1 is a schematic diagram of the commutation process. The converter needs a certain commutation area $A$ to complete the commutation process. When an AC system fault occurs, along with a decrease in $U_{L}, A$ will also increase accordingly. For the actual HVDC power transmission system, even if it is assumed that the DC current is constant and $A$ remains unchanged under a constant current controller and smoothing reactor, the commutation area inside the original commutation interval will decrease because of the decline of the commutating voltage and the leading phase. Therefore, to meet the commutation demand, it is necessary that $t 1$, the zero hours of commutation, be advanced and $t 2$, the end moment of commutation, be delayed, which will cause a decrease in the turn-off angle. Hence, at the moment of the AC fault, the inverter extinction angle decreases, along with a decline in the commutation voltage; CF occurs when the extinction angle becomes smaller than the critical extinction angle.

According to the information derived from the literature, the commutation area $A$ could be calculated as follows [16]:

$$
A_{\min }=\int_{\pi-\gamma_{\min }}^{\pi} \sqrt{2} k U_{L} \sin (\theta) \mathrm{d} \theta,
$$

where $k$ is the transformer tap ratio, $\gamma_{\min }$ is the minimum extinction angle of the converter, $U_{L}$ is the RMS value of the line-to-line voltage of the $\mathrm{CB}$, and $\theta$ is the angle of the $\mathrm{CB}$ voltage.

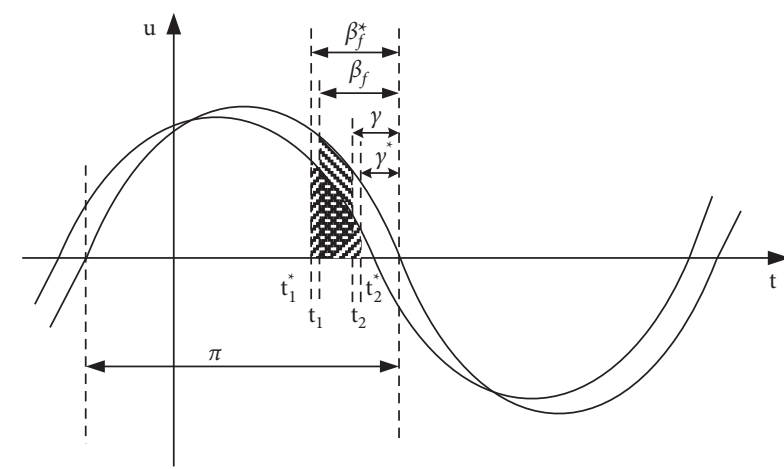

FIgUre 1: Commutation voltage-time area.

From equation (1), it can be concluded that

$$
A_{\min }=\sqrt{2} k U_{L}\left(1-\cos \gamma_{\min }\right) .
$$

The minimum extinction angle of the converter can be calculated as follows:

$$
\gamma_{\min }=\arccos \left(1-\frac{A_{\min }}{\sqrt{2} k U_{L}}\right) .
$$

The deionized response time of the high-power thyristor is around $400 \mu \mathrm{s}$. If series element error is considered, the corresponding extinction angle $\gamma_{\min }=10^{\circ}$. In the following sections, it is used as the reference value.

At the moment of an AC system fault, CB voltage drops, and the adjustment of the transformer ratio and the action of the DC system controller need a certain response time. Therefore, at the moment of the fault, the advance firing angle and ratio remain unchanged; the extinction angle decreases, along with a stepping down of the $\mathrm{CB}$ voltage. $\mathrm{CF}$ occurs when the extinction angle is smaller than the inherent limit extinction angle of the valve.

To illustrate the CF mechanism, the CIGRE HVDC standard model with a 12-pulse converter was analyzed using the electromagnetic transient analysis software PSCAD. The short-circuit ratios at the rectifier side and the inverter side were both set at 2.5. At $t=1 \mathrm{~s}$, a three-phase short-circuit ground fault occurred in the inverter $C B$, lasting $50 \mathrm{~ms}$. The results of the simulation are shown in Figure 2.

From Figure 2, it can be concluded that when a threephase short-circuit fault occurs in an AC system near the CB, the DC voltage drops significantly and DC current increases instantaneously. Similarly, when an unbalanced fault occurs in an AC system, the voltage variation of the $\mathrm{CB}$ could lead to CF.

\section{Commutation Failure Criterion}

3.1. Three-Phase Short-Circuit Fault Commutation Failure Criterion. Multi-infeed interaction factor (MIIF) is an indicator of the strength of an interaction between converter stations in a multi-infeed HVDC transmission system $[17,18]$. The multi-infeed interaction factor MIIF $_{i j}$ is defined by (4) and is essentially the voltage drop ratio at bus $i$ 

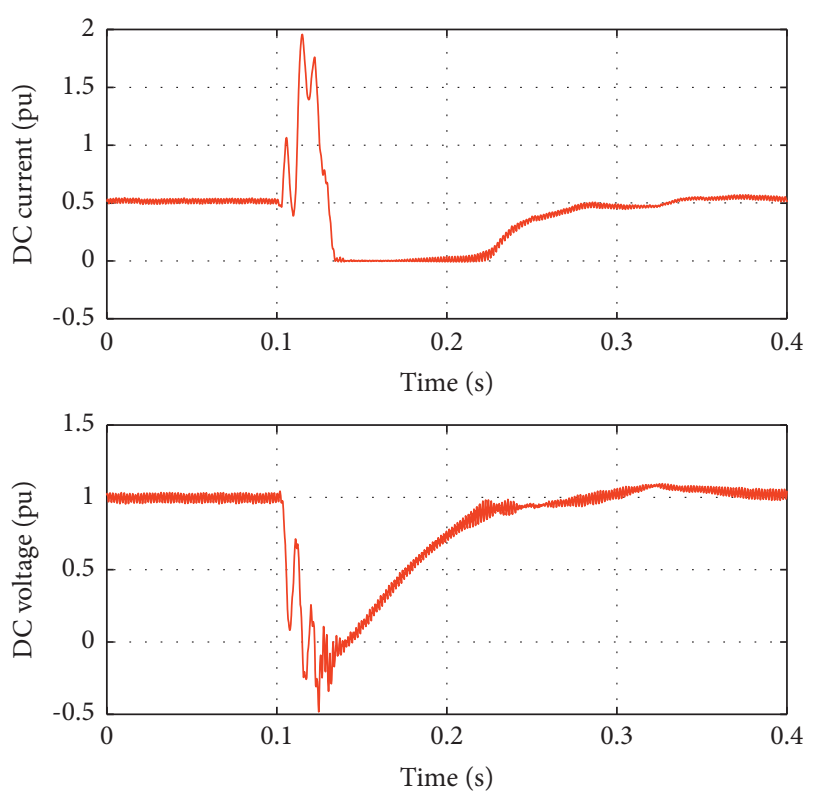

Figure 2: Simulation waveform of three-phase short-circuit ground fault.

following a $1 \%$ voltage reduction at the ac busbar of converter $j$ caused by a three-phase balanced inductive fault:

$$
\operatorname{MIIF}_{i j}=\frac{\Delta U_{i}}{1 \% U_{j 0}}=\left|\frac{Z_{i j}}{Z_{j j}}\right|,
$$

where $U_{j 0}$ is the RMS value of the line-to-line voltage of bus $j$ before the fault and $\Delta U_{j}$ is the voltage drop of the line-to-line voltage of bus $j$.

Similar to the definition of MIIF, the voltage interaction factor (VIF), $\mathrm{VIF}_{i j}$, is defined as the voltage change rate of $\mathrm{CB}$ $i$ following a $1 \%$ voltage reduction at the bus $j$ of the ac system caused by a three-phase balanced inductive fault:

$$
\mathrm{VIF}_{i j}=\frac{\Delta U_{j}}{1 \% U_{i 0}}=\left|\frac{Z_{i j}}{Z_{i i}}\right|
$$

where $Z_{i i}$ is the auto-impedance of bus $i, Z_{i j}$ is the mutual impedance between $\mathrm{CB} i$ and bus $j$, and $U_{i 0}$ and $\Delta U_{j}$ have the same meaning as in (4).

When three-phase to ground metallic short-circuit fault occurs at $\mathrm{CB} i$, bus voltage $U_{i 0}$ drops to 0 , and the voltage drop of CB $i$ is

$$
\Delta U_{i}=\operatorname{VIF}_{i j} U_{j 0} \frac{U_{i N}}{U_{j N}},
$$

where $U_{i N}$ and $U_{j N}$ are the rated voltages of CB $i$ and bus $j$, respectively.

Thus, the voltage of $\mathrm{CB} i$ is

$$
U_{i}=U_{i 0}-\Delta U_{i}=U_{i 0}-\operatorname{VIF}_{i j} U_{j 0} \frac{U_{i N}}{U_{j N}} .
$$

When the system is symmetric, the inverter extinction angle can be expressed as follows [19]:

$$
\gamma_{i}=\arccos \left(\frac{\sqrt{2} k_{i} I_{d} X_{L i}}{U_{L}}+\cos \beta\right),
$$

where $I_{d}$ is the DC current and $\beta$ is the advance trigger angle.

Substitute (7) into (8), the extinction angle of inverter $i$ can be expressed as

$$
\gamma_{i}=\arccos \left(\frac{\sqrt{2} k_{i} I_{d} X_{L i}}{U_{i 0}-\left(Z_{i j} / Z_{i i}\right) U_{j 0}\left(U_{i N} / U_{j N}\right)}+\cos \beta\right) .
$$

When three-phase to ground metallic short-circuit fault happens at $\mathrm{AC}$ bus $j, \mathrm{CF}$ will happen at the converter which is connected with $\mathrm{CB} i$ when $\gamma_{j} \leq \gamma_{\text {min }}$. This serves as a criterion of $\mathrm{CF}$ in detecting the three-phase short-circuit fault.

\subsection{Unbalanced Short-Circuit Fault Commutation Failure} Criterion. When unbalanced faults occur in the AC system, the voltage drop and phase shift of $\mathrm{CB}$ are related to the electrical distance of the fault location. To verify the CF criterion of an unbalanced fault, the vector of each phase voltage should be calculated, respectively. Then, the line-toline voltage which is corresponding to different commutation processes is calculated. Unbalanced short-circuit faults include single line-to-ground fault, double line-to-ground fault, line-to-line fault, etc. In this section, the CF criterion under different kinds of faults' conditions will be introduced in detail.

When unbalanced short-circuit fault happens at bus $j$, the voltages of $\mathrm{CB} i$ can be formulated as

$$
\left\{\begin{array}{l}
\dot{U}_{i(1)}=\dot{U}_{i 0}-\dot{I}_{j(1)} Z_{i j(1)}, \\
\dot{U}_{i(2)}=-\dot{I}_{j(2)} Z_{i j(2)}, \\
\dot{U}_{i(0)}=-\dot{I}_{j(0)} Z_{i j(0)},
\end{array}\right.
$$

where $U_{i 0}$ is the initial voltages of CB $i, U_{i(1)}, U_{\mathrm{i}(2)}$, and $U_{i(0)}$ are the positive-sequence, negative-sequence, and zero-sequence voltage components, respectively, $I_{j(1)}, I_{j(2)}$, and $I_{j(0)}$ are the three sequences short-circuit currents, and $Z_{i j(1)}$, $Z_{i j(2)}$, and $Z_{i j(0)}$ are the three sequence mutual impedances of converter $\mathrm{CB} i$ and bus $j$, respectively.

According to the symmetrical component method, the three-phase voltage of CB $i$ can be derived as

$$
\left\{\begin{array}{l}
\dot{U}_{i a}=\dot{U}_{i(1)}+\dot{U}_{i(2)}+\dot{U}_{i(0)}, \\
\dot{U}_{i b}=\alpha^{2} \dot{U}_{i(1)}+\alpha \dot{U}_{i(2)}+\dot{U}_{i(0)}, \\
\dot{U}_{i c}=\alpha \dot{U}_{i(1)}+\alpha^{2} \dot{U}_{i(2)}+\dot{U}_{i(0)} .
\end{array}\right.
$$

3.2.1. Single Line-to-Ground Fault. When a single line-toground fault occurs on phase $A$ of bus $j$, the fault conditions can be written as

$$
\dot{I}_{j(1)}=\dot{I}_{j(2)}=\dot{I}_{j(0)}=\frac{U_{j 0}}{Z_{j j(1)}+Z_{j j(2)}+Z_{j j(0)}},
$$


where $Z_{j j(1)}, Z_{j j(2)}$, and $Z_{j j(0)}$ are the impedances of the three sequences of bus $j$, respectively.

Substitute (12) into (10) and (11), the voltage variations of phase $A$ at $\mathrm{CB} i$ is

$$
\Delta U_{i a}=\left|\frac{Z_{i j(1)}+Z_{i j(2)}+Z_{i j(0)}}{Z_{j j(1)}+Z_{j j(2)}+Z_{j j(0)}} \cdot \dot{U}_{j 0}\right| .
$$

As shown in Figure 3, after a single line-to-ground fault happens, the phase voltage of phase $B$ and phase $C$ remains unchanged. According to the triangle relation, the line-toline voltage between phase $A$ and $B$ and phase $A$ and $C$ is

$$
U_{a b}^{\prime}=U_{c a}^{\prime}=\sqrt{3-3 \Delta U_{a}+\Delta U_{a}^{2}} .
$$

Therefore, the zero-crossing phase shift of the commutating voltage can be formulated as

$$
\phi=\arctan \frac{\Delta U_{a}}{\sqrt{3}\left(2-\Delta U_{a}\right)}
$$

At the moment of the fault, the converter transformer ratio remains unchanged; thus, the percentage of

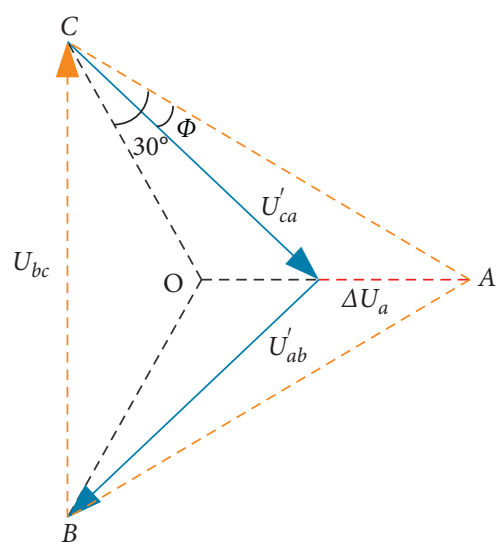

FIGURE 3: AC voltage of converter bus after a single line-to-ground fault.

commutation voltage drop and that of voltage drop at the $\mathrm{CB}$ are the same. Therefore, the extinction angle of each converter valve at the moment of phase $A$ to ground shortcircuit is

$$
\left\{\begin{array}{l}
\gamma_{i V 1, V 4}=\arccos \left(\frac{\sqrt{2} k I_{d} X_{L i}}{\sqrt{3-3 \Delta U_{a}+\Delta U_{a}^{2}} U_{L} / \sqrt{3}}+\cos \beta\right)-\arctan \frac{\Delta U_{a}}{\sqrt{3}\left(2-\Delta U_{a}\right)}, \\
\gamma_{i V 2, V 5}=\arccos \left(\frac{\sqrt{2} k I_{d} X_{L i}}{\sqrt{3-3 \Delta U_{a}+\Delta U_{a}^{2}} U_{L} / \sqrt{3}}+\cos \beta\right)+\arctan \frac{\Delta U_{a}}{\sqrt{3}\left(2-\Delta U_{a}\right)} \\
\gamma_{i V 3, V 6}=\arccos \left(\frac{\sqrt{2} k I_{d} X_{L i}}{U_{L}}+\cos \beta\right) .
\end{array}\right.
$$

According to (16), when single-phase to ground shortcircuit fault happens, the corresponding converter extinction angle $\gamma_{i}$ reaches the minimum value. When the corresponding converter extinction angle $\gamma_{i} \leq \gamma_{\min }$, CF will happen at the converter station of DC $i$.

3.2.2. Double Line-to-Ground Fault and Line-to-Line Fault. The fault conditions for a double line-to-ground fault occurring on phase $A$ and $B$ of bus $j$ can be written as

$$
\left\{\begin{array}{l}
\dot{I}_{j(1)}=\frac{\dot{U}_{j|0|}}{Z_{j j(1)}+\left(\left(Z_{j j(2)} Z_{j j(0)}\right) /\left(Z_{j j(2)}+Z_{j j(0)}\right)\right)}, \\
\dot{I}_{j(2)}=-\dot{I}_{j(1)} \frac{Z_{j j(0)}}{Z_{j j(2)}+Z_{j j(0)}}, \\
\dot{I}_{j(0)}=-\dot{I}_{j(1)} \frac{Z_{j j(2)}}{Z_{j j(2)}+Z_{j j(0)}} .
\end{array}\right.
$$

Equation (17) can be reduced as

$$
\left\{\begin{array}{l}
\dot{I}_{j(1)}=\frac{Z_{j j(2)}+Z_{j j(0)}}{k} \dot{U}_{j|0|}, \\
\dot{I}_{j(2)}=\frac{Z_{j j(0)}}{k} \dot{U}_{j|0|}, \\
\dot{I}_{j(0)}=\frac{Z_{j j(2)}}{k} \dot{U}_{j|0|},
\end{array}\right.
$$

where $k=Z_{j j(1)} Z_{j j(2)}+Z_{j j(1)} Z_{j j(0)}+Z_{j j(2)} Z_{j j(0)}$.

As shown in Figure 4, the phase voltage of phase $C$ remains unchanged after double line-to-ground fault happens; the drop voltages and angle changing of phase $A$ are equal to phase $B$. Substitute (18) into (10) and (11), the voltage variations of phase $A$ at $\mathrm{CB} i$ are

$$
\Delta U_{i a}=\left|\frac{\left[Z_{j j(0)}\left(Z_{i j(2)}-Z_{i j(1)}\right)+Z_{j j(2)}\left(Z_{i j(0)}-Z_{i j(1)}\right)\right] \cdot \dot{U}_{j 0}}{k}\right| .
$$




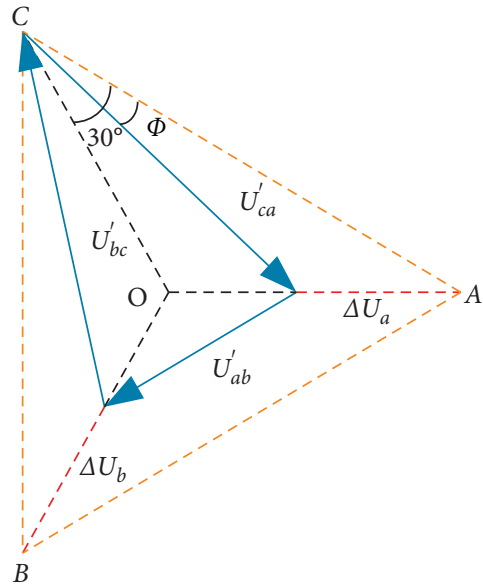

FIGURE 4: AC voltage of $\mathrm{CB}$ after double line-to-ground fault.

According to the peculiarity of the parallel triangle, after double line-to-ground fault, the line-to-line voltage between phase $\mathrm{A}$ and phase $\mathrm{B}$ is

$$
U_{a b}^{\prime}=\sqrt{3}\left(1-\Delta U_{a}\right) .
$$

Furthermore, it can be concluded from Figure 4 that the angle of $U_{a b}^{\prime}$ is not changed and the relationship of size between each line-to-line voltages is

$$
U_{c a}^{\prime}=U_{b c}^{\prime}>U_{a b}^{\prime} \text {. }
$$

Accordingly, the extinction angle $\gamma_{V 1, V 4}$ which is related to $U_{a b}{ }^{\prime}$ is smaller than the others. To reduce workload and improve the efficiency of calculation, only the line-to-line voltage between phase $A$ and phase $B$ will be calculated when the double line-to-ground fault happened. Substitute equations (19) and (20) into (6), the extinction angle $\gamma_{V 1, V 4}$ after double line-to-ground fault can be formulated as

$$
\gamma_{i V 1, V 4}=\arccos \left(\frac{\sqrt{2} k_{i} I_{d} X_{L i}}{\sqrt{3}\left(1-\Delta U_{a}\right)}+\cos \beta\right) .
$$

The fault conditions for a line-to-line fault occurring on phase $\mathrm{A}$ and $\mathrm{B}$ can be represented as

$$
\dot{I}_{j(1)}=-\dot{I}_{j(2)}=\frac{\dot{U}_{j|0|}}{Z_{j j(1)}+Z_{j j(2)}} .
$$

Like single line-to-ground fault and double line-toground fault, substituting equation (17) into (10) and (11), the voltage variations of phase $A$ and phase $B$ of $C B i$ by lineto-line fault can be formulated as

$$
\Delta U_{i a}=\Delta U_{i b}=\left|\frac{Z_{i j(1)}+Z_{i j(2)}}{Z_{j j(1)}+Z_{j j(2)}} \cdot \dot{U}_{j 0}\right| .
$$

When the line-to-line fault occurs in the AC system, the relationship of voltage phasor of $\mathrm{CB}$ is a similarity to the phasor which has occurred after double line-to-ground fault, as shown in Figure 4. Using the same process as in Section 3.2.2, the line-to-line voltage between phase $A$ and phase $B$ can be formulated as equation (20), and the extinction angle can also be formulated by an equation.
When the double line-to-line fault or line-to-line fault occurs at bus $j$, the extinction angle $\gamma_{V 1, V 4}$ of the corresponding converter at $\mathrm{CB} i$ can be calculated by equations (19), (20), (22), and (24). CF will happen at the converter which is connected with CB $i$ while $\gamma_{j} \leq \gamma_{\text {min }}$. This serves as a criterion of $\mathrm{CF}$ in detecting the line-to-line fault.

\section{The Demarcation of the Critical Failure Impedance Boundaries}

In a multi-infeed HVDC system which contains $n$ buses and $k$ HVDC systems, given static models of generators, transmission lines, transformers, loads, and HVDC systems, the steps of demarcating the critical failure impedance boundaries are as follows:

(1) Solve AC/DC network load flow and calculate the voltage of each bus.

(2) Create the impedance matrix of the system.

(3) Calculate extinction angles $\gamma\left(\gamma_{1}, \gamma_{2}, \ldots, \gamma_{k}\right)$ of every converter of the multi-infeed HVDC system in different fault conditions. After the three-phase shortcircuit fault occurs on bus $B_{i}$, the extinction angles could be calculated by equation 7 . To improve the computational efficiency, when the unbalanced fault happened on bus $B_{i}$, only $\gamma_{V 1, V 4}\left(\gamma_{1 V 1, V 4}, \gamma_{2 V 1, V 4}, \ldots\right.$, $\left.\gamma_{m V 1}, V 4\right)$ which is corresponding to the fault phase should be calculated. When single line-to-ground fault happened, $\gamma_{m V 1}, V 4$ could be calculated by equations (14)-(16). When double line-to-ground fault happened, $\gamma_{m V 1, V 4}$ could be calculated by equations (19)-(22). When a line-to-line fault happened, $\gamma_{m V 1, V 4}$ could be calculated by equations (20), (22), and (24).

(4) Form the bus sets based on the criterion $\gamma_{i j} \leq \gamma_{\min }$ which detects the CF. The bus sets are defined in (25) as follows:

$$
\begin{aligned}
B_{\text {Tfail }-i} & =\left\{B_{1}, B_{2}, \cdots, B_{k}\right\}, & & \gamma_{i} \leq \gamma_{\text {min }}, \\
B_{\text {Sfail- } i} & =\left\{B_{1}, B_{2}, \cdots, B_{k}\right\}, & & \gamma_{i V 1, V 4} \leq \gamma_{\text {min }}, \\
B_{D f \text { ail }-i} & =\left\{B_{1}, B_{2}, \cdots, B_{k}\right\}, & & \gamma_{i V 1, V 4} \leq \gamma_{\text {min }}, \\
B_{\text {Lfail-i }} & =\left\{B_{1}, B_{2}, \cdots, B_{k}\right\}, & & \gamma_{i V 1, V 4} \leq \gamma_{\text {min }} .
\end{aligned}
$$

$B_{\text {Tfail-i }}$ is the three-phase short-circuit fault bus set; when three-phase short-circuit fault occurs on any bus which is included in this bus set, it may cause the CF fault of DC converter station $i . B_{\text {Sfail-i }}$ is the single line-to-ground fault bus set when a single line-toground fault occurs on any bus which is included in this bus set, it may cause the CF of DC converter station $i$. $B_{D f a i l-i}$ is the double line-to-ground fault bus set when a double line-to-ground fault occurs on any bus which is included in this bus set, it may cause the CF of DC converter station $i$. $B_{\text {Lfail- } i}$ is the line-toline fault bus set when a line-to-line fault occurs on any bus which is included in this bus set, it may cause the CF of DC converter station $i$. 
(5) Draw the corresponding critical failure impedance boundaries and define the communication failure area according to the bus sets in step (4) on the system topological graph. The area within the critical failure impedance boundary is defined as the corresponding critical failure impedance area. If a threephase metallic short-circuit fault or single line-toground phase to Earth fault occurs in the buses located at the critical failure impedance area, it will lead to the CF of the corresponding DC system. On the contrary, if the fault occurs in the buses located outside the area, it will not lead to the CF of the corresponding DC system.

The detailed process of demarcating the critical failure impedance boundaries is shown in Figure 5.

Figure 6 shows the critical failure impedance boundaries of the three-infeed HVDC system. Short-circuit fault that occurs in the buses in the areas of B1, B2, and B3 will lead to the CF of the DC subsystem 1,2 , and 3 , respectively. If the fault occurs in the area of B12, which is the intersection of B1 and B2, CF of the DC subsystem 1 and DC subsystem 2 will happen at the same time. Therefore, this area is defined as the area where two DC systems have CFs. Similarly, B13 is the area where short-circuit fault on buses in that area will lead to CFs of DC subsystem 1 and 3 simultaneously, and B23 is the area where short-circuit fault on buses in that area will lead to CFs of DC subsystem 2 and 3 simultaneously. B123 is the intersection of B1, B2, and B3. Fault happens on buses within that area will lead to CFs of DC subsystem 1, 2, and 3 simultaneously. On the contrary, fault that occurs outside all these above areas will not lead to CF in any DC subsystem.

Compared with the common method which detects the CF utilizing electromagnetic simulation software, the proposed method uses the minimum extinction angle as the criterion and identifies critical impedance area quickly and accurately through a simple calculation. The identified critical impedance area provides a clear and direct perspective to the system operators of the area where faults will be critical to DC CF of the DC system. Moreover, it will provide valuable information for system planning and protection design.

\section{Case Studies}

In this section, the proposed method of detecting CFs' critical impedance boundaries is validated on the IEEE 39bus and 118-bus test systems. Based on the CIGRE HVDC standard model, the quasi-steady-state model is adopted in the multi-infeed DC system.

5.1. Study of IEEE 39-Bus Test System. Three-infeed HVDC systems are established in the IEEE 39-bus test system; parameters of the three HVDC systems are listed in Table 1.

Following the steps in Section 4, the extinction angles of the three-infeed HVDC system in different fault conditions are calculated by substituting the above parameters of the three-infeed HVDC system into formulas (9), (16), and (22).
The detailed calculations of the extinction angle are given in Table 2.

While the calculated extinction angle is less than $\gamma_{\text {min }}$, the corresponding bus is highlighted in Table 2. Put these buses into fault bus sets of different fault type. Take HVDC 1 as example, its three-phase short-circuit fault bus set $B_{\text {Tfail-1 }}$ contains 33 buses, the single line-to-ground fault bus set $B_{\text {Sfail-1 }}$ contains 12 buses, the double line-to-ground fault bus set $B_{\text {Dfail-1 }}$ contains 28 buses, and the line-to-line fault bus set $B_{\text {Lfail-1 }}$ contains 14 buses. The result is consistent with the severity of bus fault. When three-phase short-circuit fault happens, the voltage drop of $\mathrm{CB}$ is largest in four fault conditions. The second largest voltage drop occurs when double line-to-ground fault happens. However, for single line-to-ground fault and line-to-line fault, the number of fault bus set cannot be directly compared and needs to be calculated based on the method proposed in this paper. For example, the number of $B_{\text {Sfail-1 }}$ is less than the number of $B_{L f a i l-1}$, but the number of $B_{S f a i l-3}$ is greater than the number of $B_{\text {Lfail-3. }}$.

Then, demarcate the critical failure impedance boundaries of the three-infeed HVDC system in different fault conditions based on these fault bus sets. The detailed results are shown in Figure 7.

As shown in Figure 7, some buses are included in the overlap region of different critical failure impedance boundaries. When the corresponding fault occurs on these buses, it may cause CF in more than one HVDC system. Some buses are included in the nonoverlap region. When the corresponding fault occurs on these buses, it may cause CF in only one HVDC system. Therefore, the effectiveness of critical failure impedance boundaries can be verified by conducting different types of faults simulation of the buses in the overlap region and some other buses in the nonoverlap region. The three-phase short-circuit fault simulation is conducted on bus 9 and bus 24, the single line-to-ground fault simulation is conducted on bus 5 and bus 15 , the double line-to-ground fault simulation is conducted on bus 14 and bus 20, and line-to-line fault simulation is conducted on bus 3 and bus 27 .

Case 1. $t=0.5 \mathrm{~s}$; a three-phase short-circuit ground fault occurs on bus 24 and lasts $0.1 \mathrm{~s}$. The simulation result is shown in Figure 8.

Case 2. $t=0.5 \mathrm{~s}$; a three-phase short-circuit ground fault occurs on bus 9 and lasts $0.1 \mathrm{~s}$. The simulation result is shown in Figure 9.

In Table 2, $\gamma_{1,24}=9.14^{\circ}, \gamma_{2,24}=9.06^{\circ}$, and $\gamma_{3,24}=9.23^{\circ}$, and they are all less than $\gamma_{\text {min }}$. According to the calculation results, when three-phase short-circuit fault is applied at bus 24, CF fault will occur on three HVDC systems at the same time, the three inverters will be blocked, and their DC power drops to $0 \mathrm{MW}$. The calculation results are the same as the simulated waveforms shown in Figure 8. In Table 2, $\gamma_{1,9}=11.17^{\circ}, \gamma_{2,9}=11.24^{\circ}$, and $\gamma_{3,9}=7.63^{\circ}$, and they are all less than $\gamma_{\text {min }}$. According to the calculation results, when threephase short-circuit fault is applied at bus 9, the DC powers of HVDC 1 and HVDC 2 drop slightly and CF only occurs on 


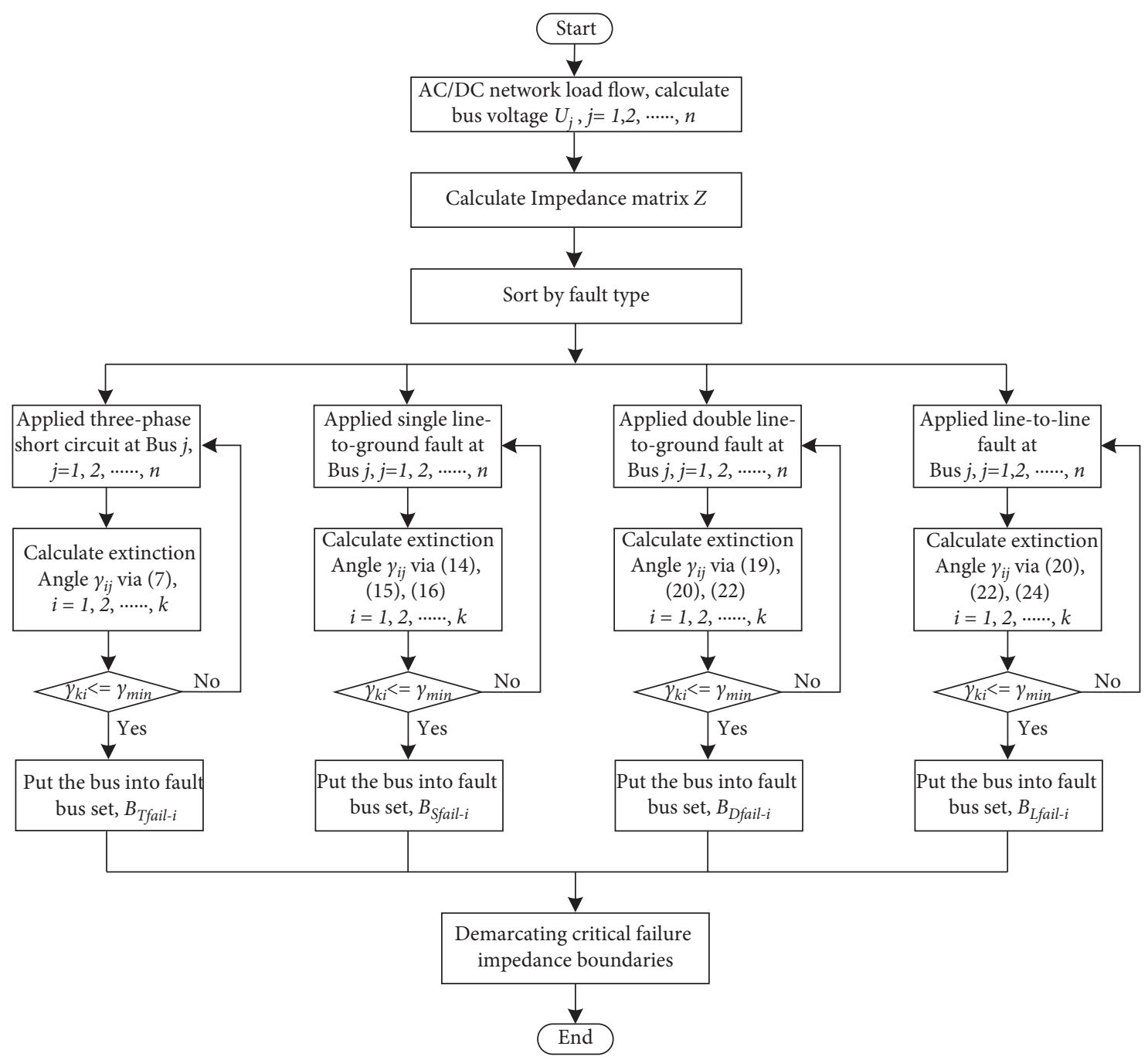

FIGURE 5: Flowchart of delimiting critical failure impedance boundaries of the multi-infeed HVDC system.

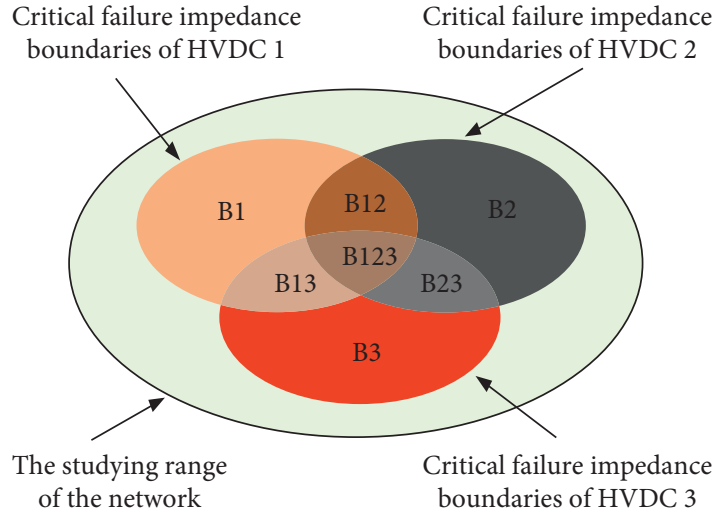

FIGURE 6: Critical failure impedance boundaries of the three-infeed HVDC system.

HVDC 3. The calculation results are the same as the simulated waveforms shown in Figure 9. Thus, the results of the dynamic simulation are consistent with the results of critical impedance boundaries for three-phase short-circuits' ground fault proposed in this paper.
Case 3. $t=0.5 \mathrm{~s}$; a single line-to-ground fault occurs on bus 15 and lasts $0.1 \mathrm{~s}$. The simulation result is shown in Figure 10.

Case 4. $t=0.5 \mathrm{~s}$; a single line-to-ground fault occurs on bus 5 and lasts $0.1 \mathrm{~s}$. The simulation result is shown in Figure 11.

In Table $2, \gamma_{1,15}=9.40^{\circ}, \gamma_{2,15}=8.61^{\circ}$, and $\gamma_{3,15}=9.72^{\circ}$, and they are all less than $\gamma_{\text {min. }}$. According to the calculation results, when a single line-to-ground fault is applied at bus 15, CF fault will occur on three HVDC systems at the same time, the three inverters will be blocked, and their DC powers drop to $0 \mathrm{MW}$. The calculation results are the same as the simulation waveforms which are shown in Figure 10. In Table 2, $\gamma_{1,5}=12.96^{\circ}, \gamma_{2,5}=11.45^{\circ}$, and $\gamma_{3,5}=8.70^{\circ}$, and only $\gamma_{3,5}$ is less than $\gamma_{\text {min }}$. According to the calculation results, when a single line-to-ground fault is applied at bus 5, the DC powers of HVDC 1 and HVDC 2 drop slightly and CF only occurs on HVDC 3. The calculation results are the same as the simulation waveforms which are shown in Figure 11. Therefore, the results of the dynamic simulation are consistent with the results of critical impedance boundaries for single line-to-ground fault proposed in this paper. 
TABLE 1: Parameter of the three-infeed HVDC system.

\begin{tabular}{|c|c|c|c|c|c|c|c|c|c|}
\hline Subsystem & Rectifier bus & Inverter bus & Control mode & $P_{D C}(\mathrm{MW})$ & $V_{D C}(\mathrm{kV})$ & $R_{D C}(\Omega)$ & $X_{L}(\%)$ & $\beta$ & K \\
\hline HVDC 1 & Bus 25 & Bus 18 & Constant-power & 200 & 500 & 7.854 & 15 & $38.4^{\circ}$ & 1.0 \\
\hline HVDC 2 & Bus 29 & Bus 17 & Constant-power & 200 & 500 & 7.854 & 15 & $38.4^{\circ}$ & 1.0 \\
\hline HVDC 3 & Bus 36 & Bus 13 & Constant-power & 200 & 500 & 7.854 & 15 & $38.4^{\circ}$ & 1.0 \\
\hline
\end{tabular}

TABLE 2: Extinction angles of the three-infeed HVDC system in different faults.

\begin{tabular}{|c|c|c|c|c|c|c|c|c|c|c|c|c|}
\hline \multirow{2}{*}{$\begin{array}{l}\text { Bus } \\
\text { number }\end{array}$} & \multicolumn{3}{|c|}{$\begin{array}{c}\text { Three-phase short-circuit } \\
\text { fault }\end{array}$} & \multicolumn{3}{|c|}{ Single line-to-ground fault } & \multicolumn{3}{|c|}{ Double line-to-ground fault } & \multicolumn{3}{|c|}{ Line-to-line fault } \\
\hline & HVDC 1 & HVDC 2 & HVDC 3 & HVDC 1 & HVDC 2 & HVDC 3 & HVDC 1 & HVDC 2 & HVDC 3 & HVDC 1 & HVDC 2 & HVDC 3 \\
\hline 1 & 12.40 & 12.46 & 12.24 & 15.99 & 15.93 & 15.36 & 18.76 & 18.65 & 16.00 & 16.80 & 16.74 & 16.80 \\
\hline 2 & 8.36 & 8.44 & 8.48 & 8.68 & 8.40 & 8.55 & 14.01 & 12.09 & 9.17 & 7.78 & 7.69 & 16.91 \\
\hline 3 & 7.92 & 8.10 & 8.11 & 9.06 & 9.74 & 9.48 & 8.84 & 8.94 & 8.98 & 8.04 & 7.90 & 9.72 \\
\hline 4 & 8.50 & 8.56 & 7.87 & 9.03 & 8.43 & 4.42 & 8.96 & 9.03 & 8.51 & 7.71 & 7.65 & 7.94 \\
\hline 5 & 8.98 & 9.01 & 8.28 & 12.96 & 11.45 & 8.70 & 9.09 & 9.19 & 8.17 & 7.50 & 17.45 & 8.13 \\
\hline 6 & 9.05 & 9.07 & 8.33 & 10.77 & 16.31 & 8.88 & 9.10 & 9.20 & 8.08 & 17.47 & 17.42 & 8.08 \\
\hline 7 & 9.21 & 9.23 & 8.74 & 12.90 & 11.28 & 9.69 & 9.21 & 9.32 & 7.79 & 17.30 & 17.25 & 8.09 \\
\hline 8 & 9.23 & 9.25 & 8.82 & 14.63 & 12.99 & 8.48 & 9.25 & 9.40 & 7.93 & 17.34 & 17.29 & 7.86 \\
\hline 9 & 11.17 & 11.24 & 7.63 & 15.98 & 15.49 & 11.95 & 12.79 & 12.71 & 12.28 & 16.69 & 16.64 & 9.88 \\
\hline 10 & 9.22 & 9.23 & 7.85 & 16.16 & 15.07 & 9.15 & 8.99 & 9.08 & 7.45 & 17.37 & 17.33 & 17.00 \\
\hline 11 & 9.22 & 9.23 & 8.22 & 16.56 & 15.34 & 9.29 & 9.03 & 9.13 & 7.59 & 17.38 & 17.34 & 8.22 \\
\hline 12 & 7.34 & 7.39 & 5.09 & 14.53 & 14.08 & 16.39 & 9.12 & 9.09 & 9.83 & 16.34 & 16.31 & 8.15 \\
\hline 13 & 9.20 & 9.21 & 7.33 & 17.09 & 17.16 & 5.41 & 8.96 & 9.03 & 7.47 & 17.41 & 17.38 & 7.01 \\
\hline 14 & 8.71 & 8.72 & 7.77 & 7.36 & 6.86 & 8.43 & 8.94 & 8.96 & 8.28 & 7.63 & 7.61 & 8.35 \\
\hline 15 & 8.72 & 8.64 & 8.66 & 9.40 & 8.61 & 9.72 & 8.73 & 8.62 & 8.67 & 7.69 & 7.75 & 8.22 \\
\hline 16 & 8.34 & 8.16 & 8.51 & 5.68 & 8.71 & 8.05 & 8.73 & 8.61 & 8.94 & 7.89 & 7.99 & 7.81 \\
\hline 17 & 7.85 & 7.53 & 8.31 & 8.93 & 5.41 & 12.68 & 8.72 & 8.60 & 9.06 & 8.12 & 8.26 & 7.82 \\
\hline 18 & 7.52 & 8.00 & 8.41 & 5.41 & 9.93 & 7.99 & 8.52 & 8.69 & 9.03 & 8.27 & 8.02 & 7.85 \\
\hline 19 & 7.56 & 7.35 & 7.76 & 15.21 & 11.11 & 16.41 & 9.43 & 9.60 & 9.21 & 16.84 & 6.92 & 7.80 \\
\hline 20 & 6.66 & 6.46 & 11.77 & 13.09 & 13.71 & 14.29 & 9.24 & 9.30 & 12.14 & 15.80 & 15.85 & 16.78 \\
\hline 21 & 8.53 & 8.38 & 8.69 & 12.06 & 6.26 & 16.03 & 10.00 & 10.20 & 9.39 & 7.32 & 7.40 & 15.75 \\
\hline 22 & 17.77 & 17.56 & 7.96 & 17.83 & 13.77 & 13.24 & 9.47 & 9.69 & 9.19 & 16.97 & 7.05 & 17.25 \\
\hline 23 & 7.60 & 7.39 & 7.80 & 13.04 & 18.24 & 16.98 & 9.41 & 9.58 & 9.17 & 16.88 & 16.96 & 16.91 \\
\hline 24 & 9.14 & 9.06 & 9.23 & 5.73 & 9.37 & 9.26 & 8.42 & 8.19 & 8.82 & 7.61 & 7.70 & 16.82 \\
\hline 25 & 8.62 & 8.66 & 8.75 & 6.54 & 6.90 & 7.02 & 9.01 & 9.08 & 9.23 & 7.60 & 17.54 & 7.54 \\
\hline 26 & 9.04 & 9.00 & 9.17 & 7.33 & 7.92 & 6.98 & 9.03 & 8.94 & 17.56 & 7.53 & 7.56 & 17.52 \\
\hline 27 & 8.83 & 8.74 & 9.04 & 8.60 & 7.45 & 9.49 & 8.79 & 8.64 & 10.45 & 7.68 & 7.75 & 12.14 \\
\hline 28 & 17.19 & 7.12 & 17.49 & 13.86 & 13.27 & 13.80 & 17.04 & 18.07 & 16.85 & 16.11 & 16.13 & 17.48 \\
\hline 29 & 7.09 & 7.02 & 17.38 & 13.61 & 13.94 & 13.92 & 15.04 & 11.07 & 16.86 & 16.02 & 16.04 & 16.00 \\
\hline 30 & 8.14 & 8.23 & 18.25 & 16.03 & 15.84 & 15.21 & 9.22 & 9.09 & 16.99 & 16.68 & 16.61 & 15.91 \\
\hline 31 & 7.21 & 7.28 & 5.83 & 13.93 & 13.70 & 9.19 & 13.09 & 9.06 & 9.48 & 15.75 & 15.72 & 16.63 \\
\hline 32 & 7.33 & 7.38 & 5.08 & 13.42 & 13.16 & 7.35 & 14.12 & 9.09 & 9.75 & 15.94 & 15.91 & 6.15 \\
\hline 33 & 6.69 & 6.49 & 16.81 & 12.12 & 12.67 & 12.42 & 9.23 & 9.30 & 13.14 & 15.73 & 15.79 & 6.54 \\
\hline 34 & 6.15 & 5.99 & 16.17 & 12.07 & 12.61 & 12.37 & 9.17 & 9.21 & 12.12 & 14.63 & 14.66 & 15.68 \\
\hline 35 & 16.87 & 6.67 & 17.01 & 13.13 & 13.08 & 13.91 & 15.24 & 12.31 & 15.13 & 16.06 & 16.12 & 14.60 \\
\hline 36 & 6.38 & 6.21 & 16.45 & 12.96 & 12.05 & 12.84 & 15.18 & 17.22 & 15.11 & 15.33 & 15.38 & 16.01 \\
\hline 37 & 7.48 & 7.55 & 17.63 & 14.26 & 14.56 & 14.06 & 14.13 & 18.10 & 16.98 & 16.22 & 16.18 & 15.29 \\
\hline 38 & 16.60 & 6.54 & 16.83 & 12.69 & 12.79 & 12.17 & 12.05 & 17.08 & 16.93 & 15.09 & 15.10 & 16.16 \\
\hline 39 & 8.03 & 8.11 & 17.66 & 15.64 & 15.17 & 16.03 & 13.80 & 16.72 & 18.09 & 16.61 & 16.56 & 15.01 \\
\hline Total & 33 & 36 & 27 & 12 & 13 & 20 & 28 & 28 & 24 & 14 & 14 & 19 \\
\hline
\end{tabular}

Case 5. $t=0.5 \mathrm{~s}$; a double line-to-ground fault occurs on bus 14 and lasts $0.1 \mathrm{~s}$. The simulation result is shown in Figure 12.

Case 6. $t=0.5 \mathrm{~s}$; a double line-to-ground fault occurs on bus 20 and lasts $0.1 \mathrm{~s}$. The simulation result is shown in Figure 13.

In Table $2, \gamma_{1,14}=8.94^{\circ}, \gamma_{2,14}=8.96^{\circ}$, and $\gamma_{3,14}=8.28^{\circ}$, and they are all less than $\gamma_{\text {min }}$. According to the calculation results, when a double line-to-ground fault is applied at bus
14, CF fault will occur on three HVDC systems at the same time, the three inverters will be blocked, and their DC powers drop to $0 \mathrm{MW}$. The calculation results are the same as the simulation waveforms which are shown in Figure 12. In Table 2, $\gamma_{1,20}=9.24^{\circ}, \gamma_{2,20}=9.30^{\circ}$, and $\gamma_{3,20}=12.14^{\circ}$, and only $\gamma_{1,20}$ and $\gamma_{2,20}$ are less than $\gamma_{\text {min }}$. According to the calculation results, when a double line-to-ground fault is applied at bus 20 , the DC powers of HVDC 3 drop slightly and CF only 


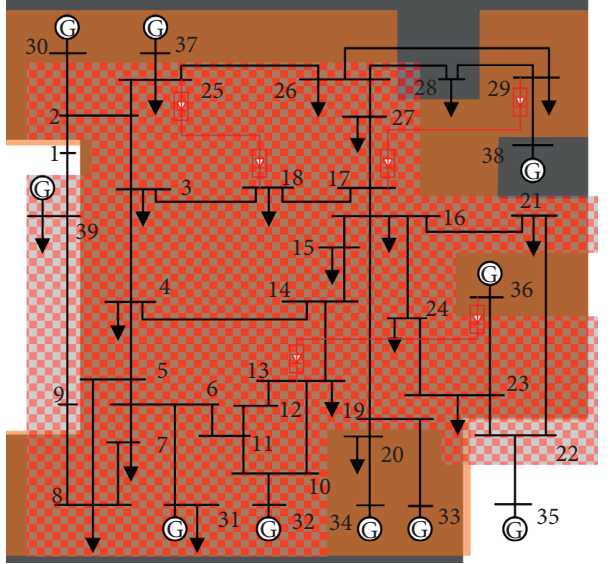

HVDC-1
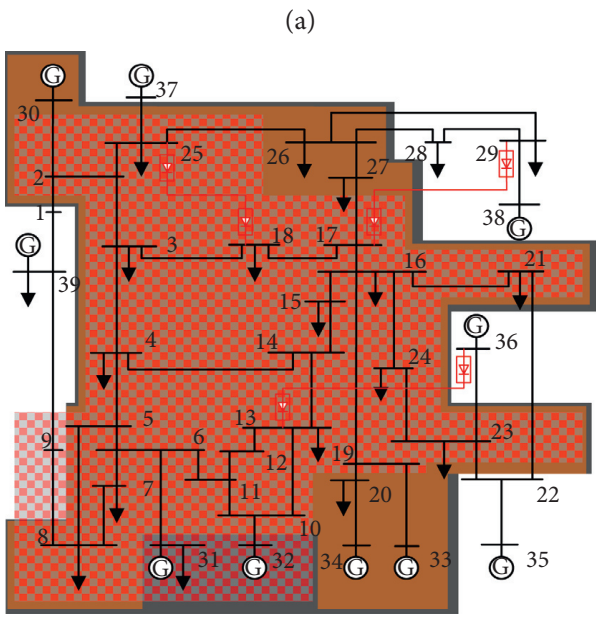

HVDC-1

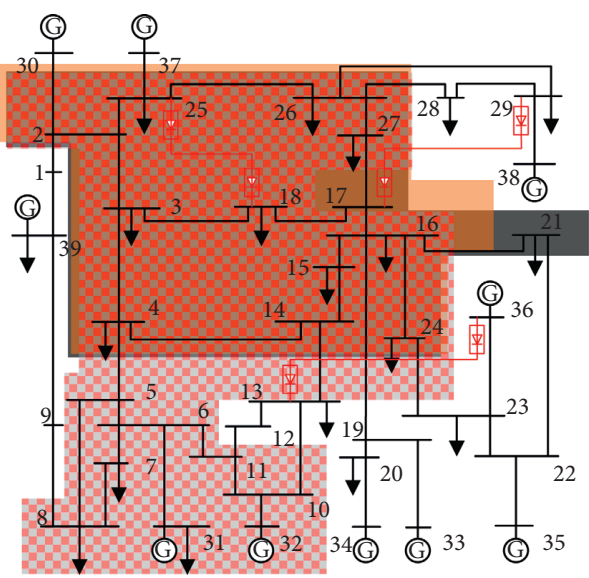

HVDC-1

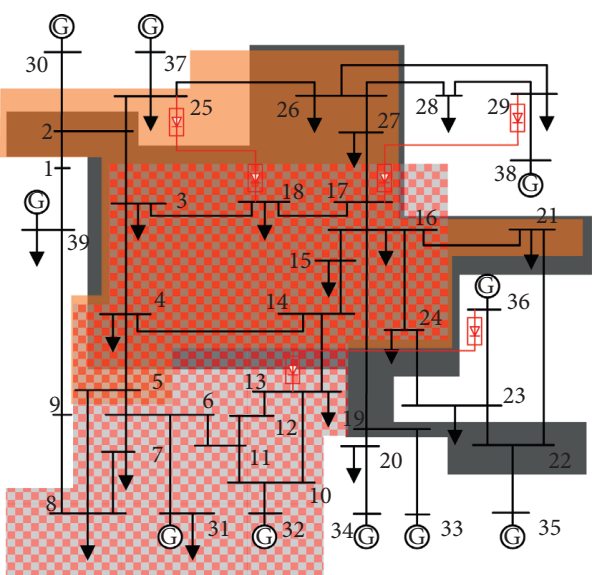

HVDC-1

(d)

FIGURE 7: Critical failure impedance boundaries of the IEEE 39-bus test system. (a) Three-phase short-circuit fault boundary. (b) Single lineto-ground fault boundary. (c) Double line-to-ground fault boundary. (d) Line-to-line fault boundary.

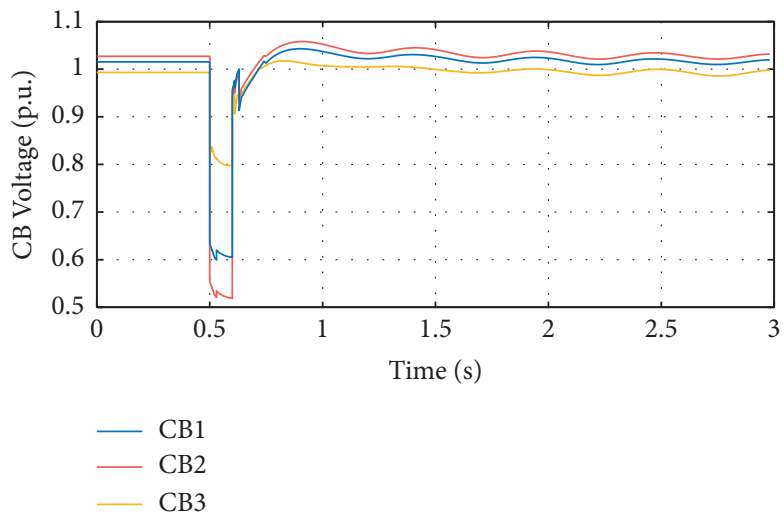

(a)

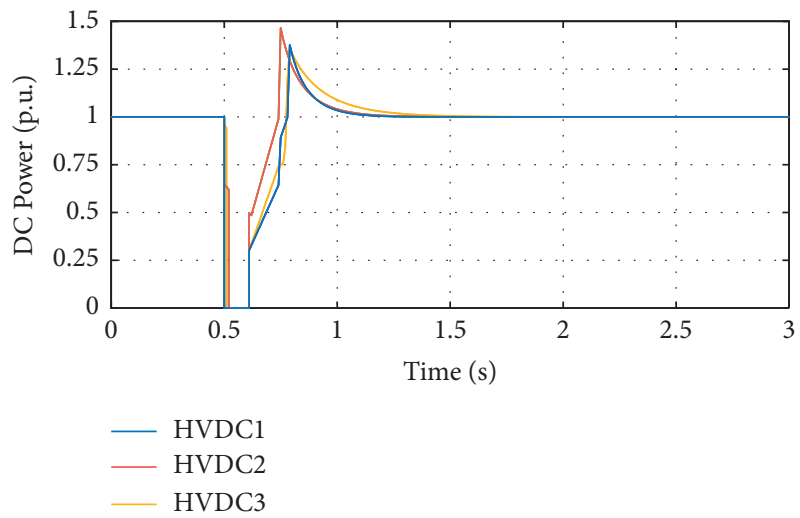

(b)

Figure 8: Simulation waveform of fault at bus 24. (a) CB voltage. (b) DC power. 


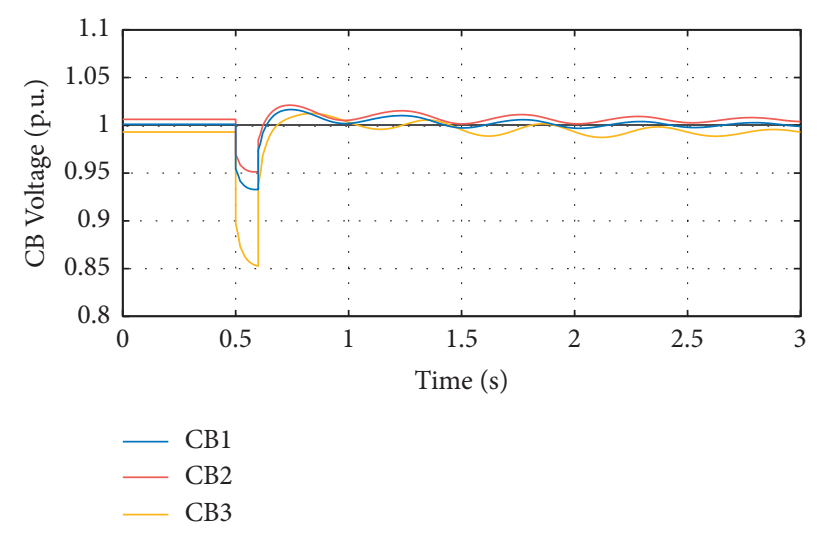

(a)

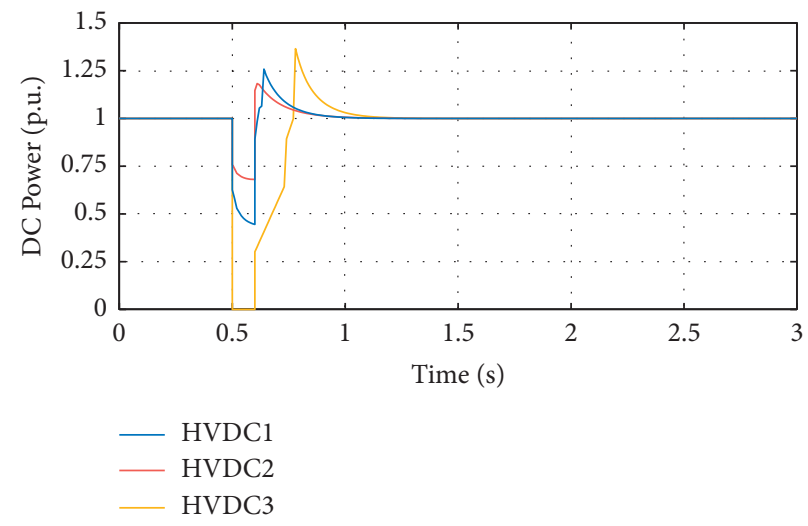

(b)

FIGURE 9: Simulation waveform of fault at bus 9. (a) CB voltage. (b) DC power.

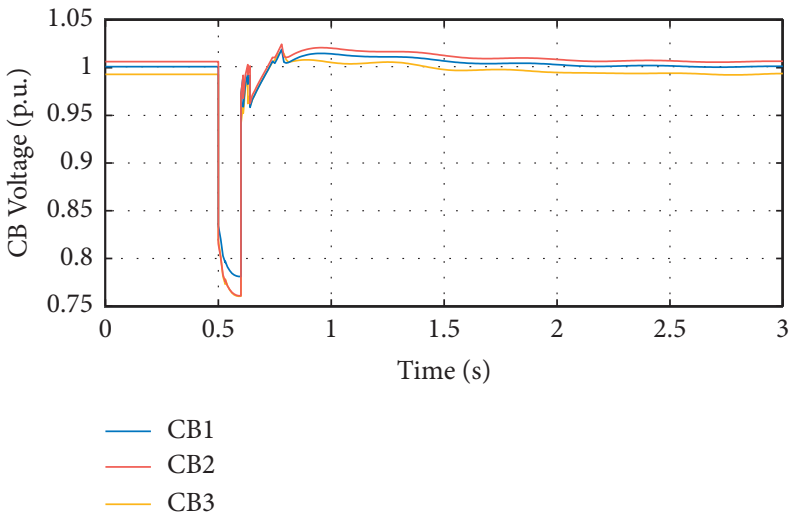

(a)

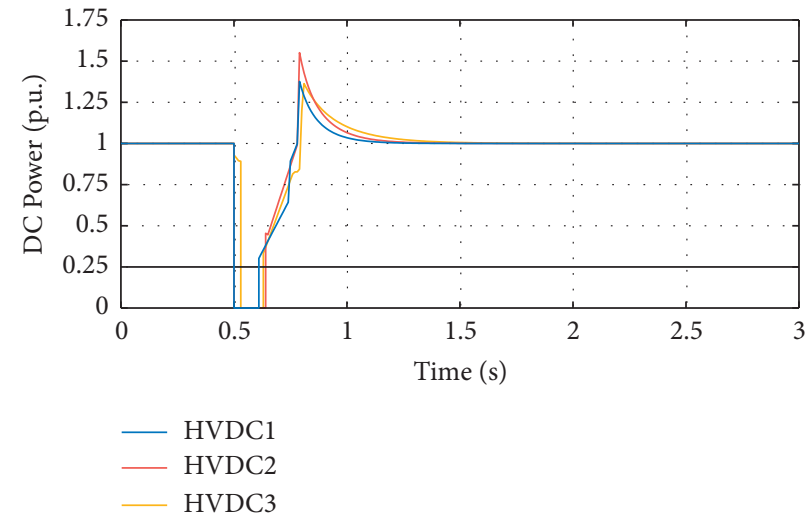

(b)

FIgURE 10: Simulation waveform of fault at bus 15. (a) CB voltage. (b) DC power.

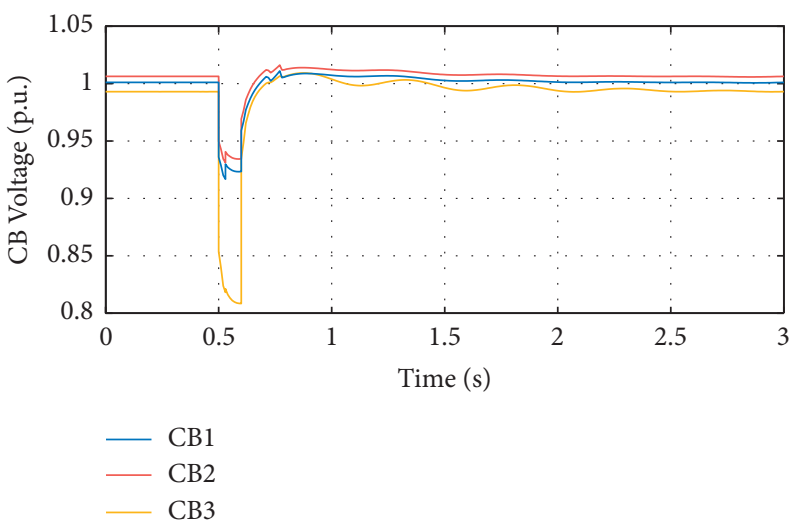

(a)

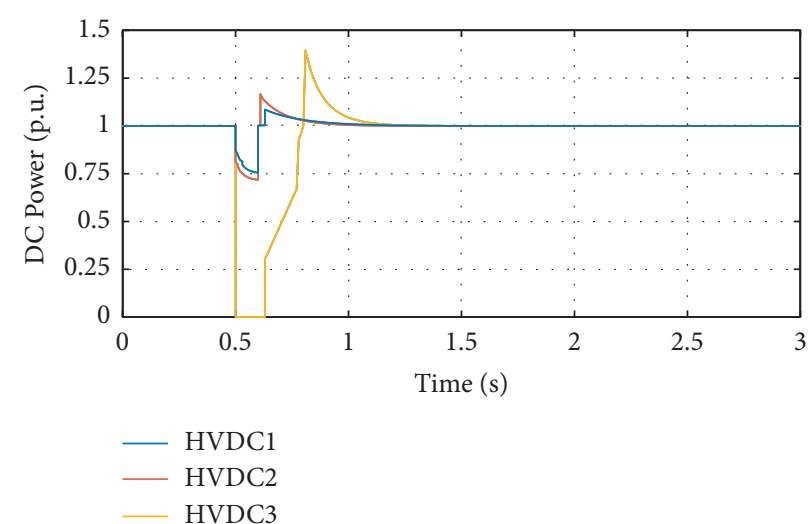

(b)

FIGURE 11: Simulation waveform of fault at bus 5. (a) CB voltage; (b) DC power. 


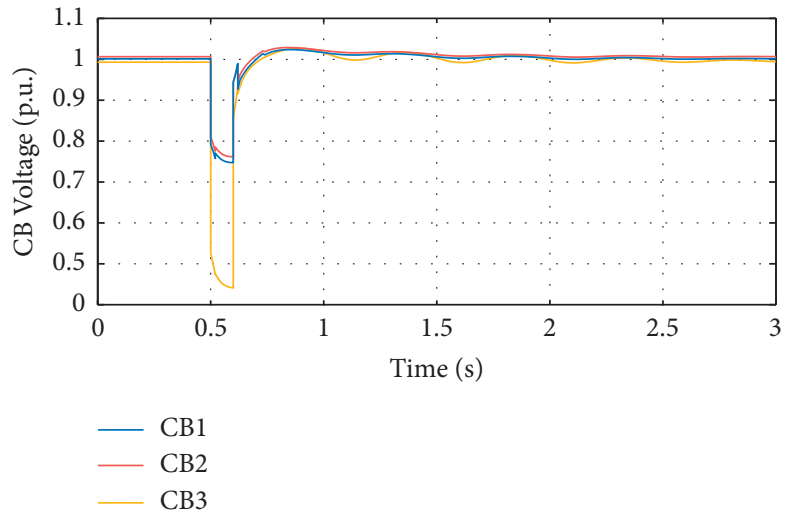

(a)

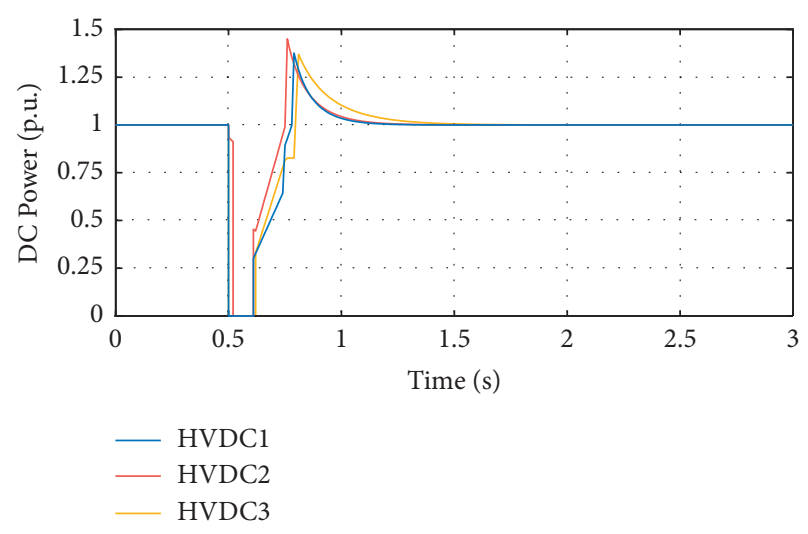

(b)

FIgURE 12: Simulation waveform of fault at bus 14. (a) CB voltage; (b) DC power.

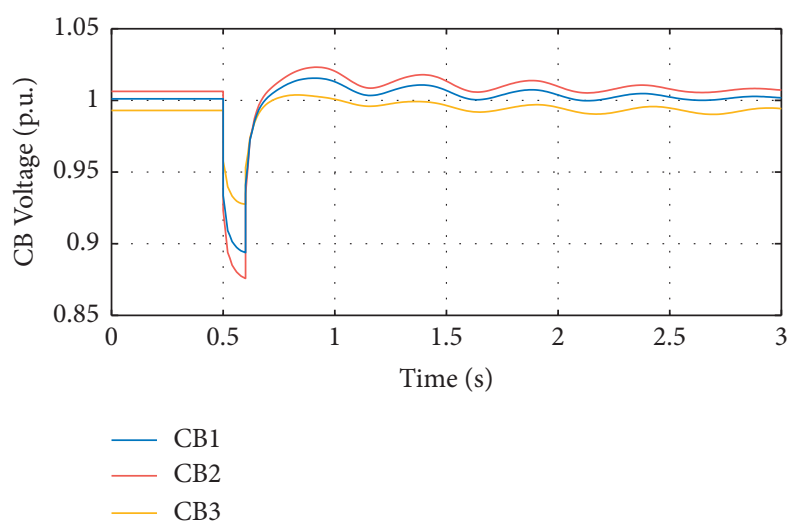

(a)

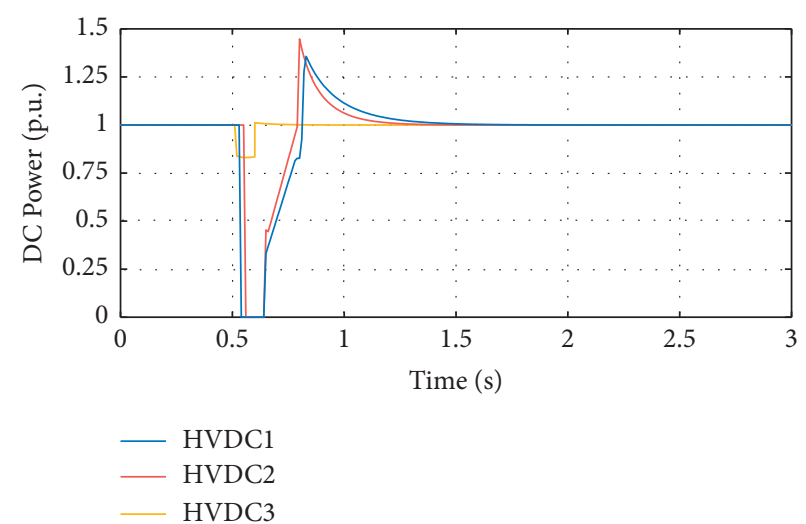

(b)

FIgURE 13: Simulation waveform of fault at bus 20. (a) CB voltage. (b) DC power.

occurs on HVDC 1 and HVDC 2 . The calculation results are the same as the simulation waveforms which are shown in Figure 13. Therefore, the results of the dynamic simulation are consistent with the results of critical impedance boundaries for double line-to-ground fault proposed in this paper.

Case 7. $t=0.5 \mathrm{~s}$; a line-to-line fault occurs on Bus 3 and lasts $0.1 \mathrm{~s}$. The simulation result is shown in Figure 14 .

Case 8. $t=0.5 \mathrm{~s}$; a line-to-line fault occurs on bus 27 and lasts $0.1 \mathrm{~s}$. The simulation result is shown in Figure 15.

In Table 2, $\gamma_{1,3}=8.04^{\circ}, \gamma_{2,3}=7.90^{\circ}$, and $\gamma_{3,3}=9.72^{\circ}$, and they are all less than $\gamma_{\mathrm{min}}$. According to the calculation results, when a line-to-line fault is applied at bus 3, CF fault will occur on three HVDC systems at the same time, the three inverters will be blocked, and their DC powers drop to $0 \mathrm{MW}$. The calculation results are the same as the simulation waveforms which are shown in Figure 14. In Table 2, $\gamma_{1,27}=7.68^{\circ}, \gamma_{2,27}=7.75^{\circ}$, and $\gamma_{3,27}=12.14^{\circ}$, and they are all less than $\gamma_{\mathrm{min}}$. According to the calculation results, when a line-to-line fault is applied at bus 27, the DC powers of
HVDC 1 and HVDC 2 drop slightly and CF only occurs on HVDC 3 . The calculation results are the same as the simulation waveforms which are shown in Figure 15. Therefore, the results of the dynamic simulation are consistent with the results of critical impedance boundaries for line-to-line fault proposed in this paper.

From what has been discussed above, the result of PSS/E dynamic simulation is consistent with the result of the proposed method, which verifies the effectiveness and accuracy of the method proposed in this paper. The critical failure impedance boundaries cannot only detect $\mathrm{CF}$ of a single HVDC system but also detect simultaneous CFs of multi-infeed HVDC systems. The calculation result is not limited by the location of the converter bus, the scale of the AC system, the capacity of the HVDC system, and the number of the multi-infeed HVDC system.

5.2. IEEE 118-Bus Test System. Three-infeed HVDC systems are established in the IEEE 118-bus test system, and parameters of the three HVDC systems are listed in Table 3.

The critical impedance boundaries of the three-infeed HVDC systems in different fault conditions are demarcated 


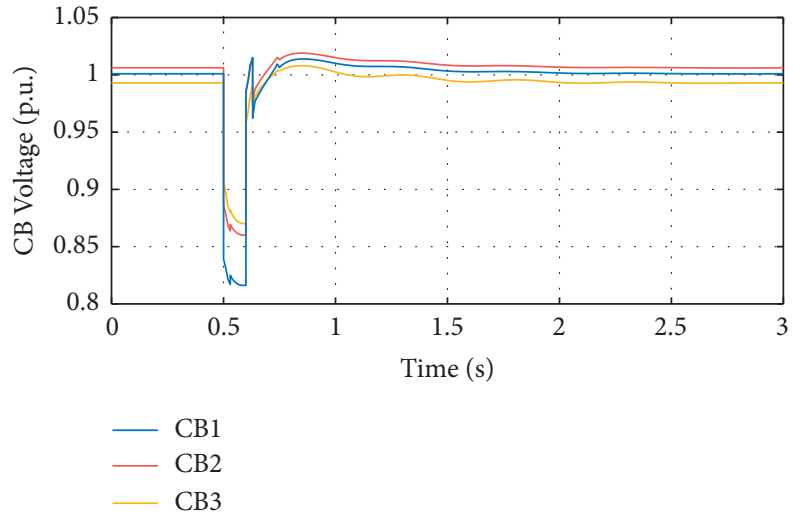

(a)

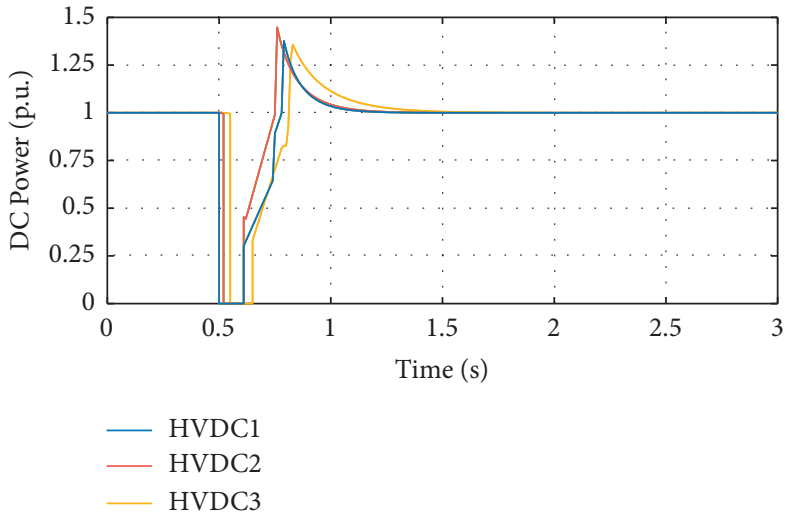

(b)

Figure 14: Simulation waveform of fault at bus 3. (a) CB voltage. (b) DC power.

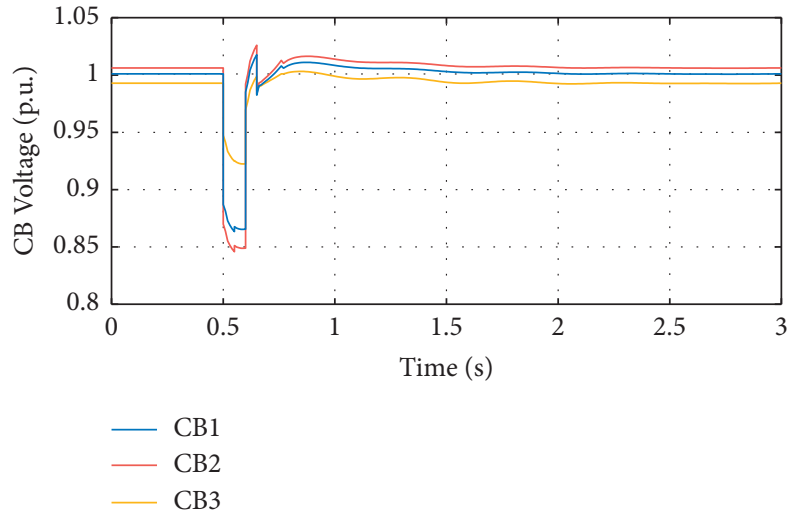

(a)

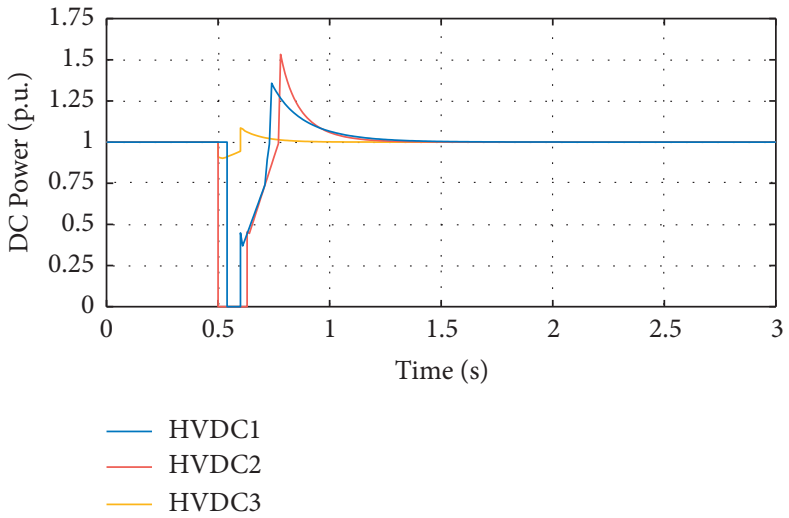

(b)

FIgURE 15: Simulation waveform of fault at bus 27. (a) CB voltage. (b) DC power.

TABle 3: Parameters of the three-infeed HVDC system.

\begin{tabular}{|c|c|c|c|c|c|c|c|c|}
\hline Subsystem & Rectifier bus & Inverter bus & Control mode & PDC (MW) & VDC $(\mathrm{kV})$ & $\operatorname{RDC}(\Omega)$ & XL (\%) & $\beta\left({ }^{\circ}\right)$ \\
\hline HVDC 1 & Bus 77 & Bus 41 & Constant-power & 800 & 525 & 8.20 & 15 & 36.8 \\
\hline HVDC 2 & Bus 25 & Bus 47 & Constant-power & 800 & 525 & 8.20 & 15 & 36.8 \\
\hline HVDC 3 & Bus 65 & Bus 54 & Constant-power & 800 & 525 & 8.20 & 15 & 36.8 \\
\hline
\end{tabular}

by the method which is proposed in this paper. The results are shown in Figure 16.

The corresponding critical failure areas which will cause CF in different HVDC systems are clearly shown in Figure 8. The application of the method which is proposed in this paper is demonstrated in a large-scale system. For a largescale system, a vast workload would be used to set up an electromagnetic transient simulation system by the traditional method and cost a lot of time and much work to simulate them. However, only detailed parameters of the $\mathrm{AC} / \mathrm{DC}$ system are required, and the method which is proposed in this paper could demarcate the critical failure impedance boundaries of the large-scale system more efficiently. This method is not limited by the scale of the AC system, and the calculation can cover all the systems.

In a practical power grid, the dispatch department of the power grid can make corresponding security strategy according to critical failure impedance boundaries, and the operation department should strengthen the inspection and detection of buses in critical failure areas. This method can also be applied in the preliminary planning of the power grid. 


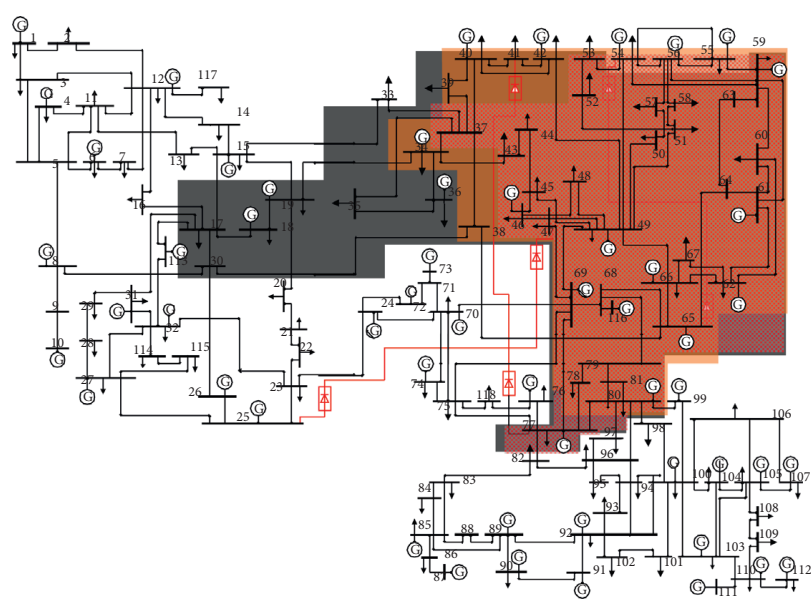

(a)

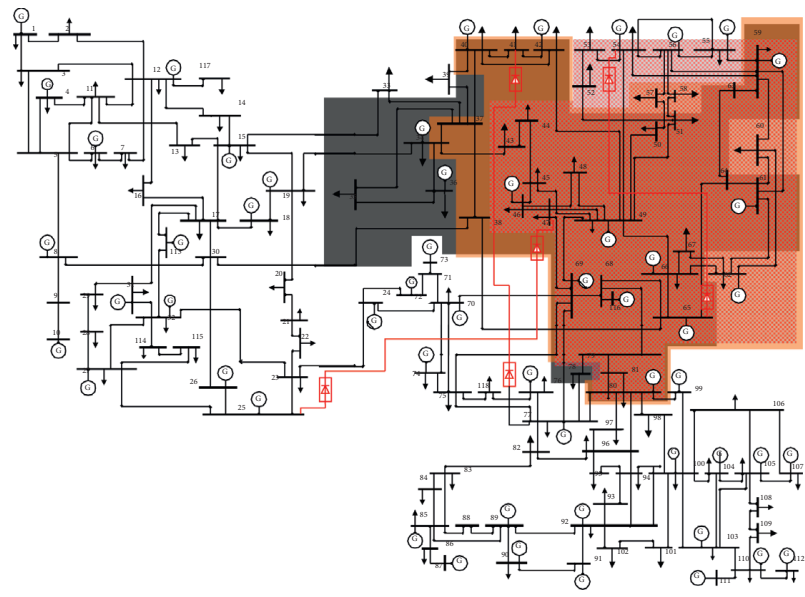

(c)

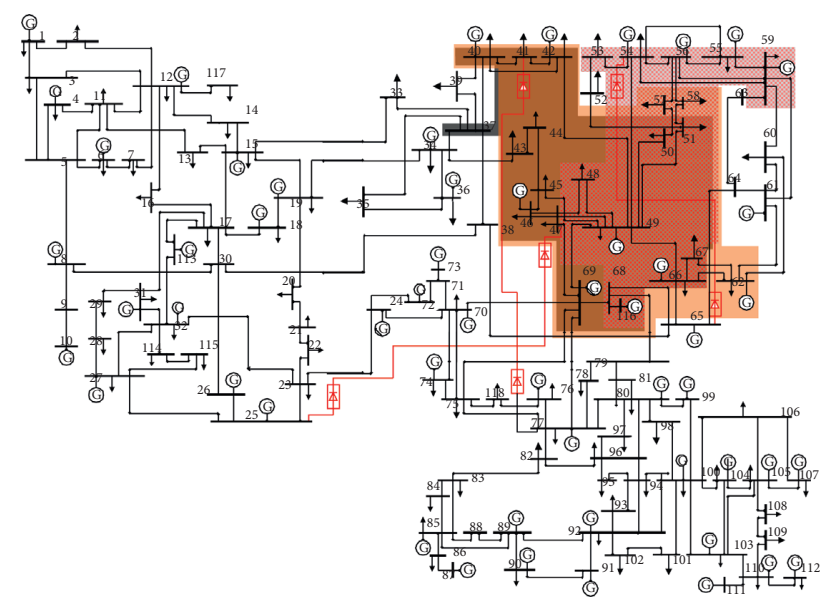

(b)

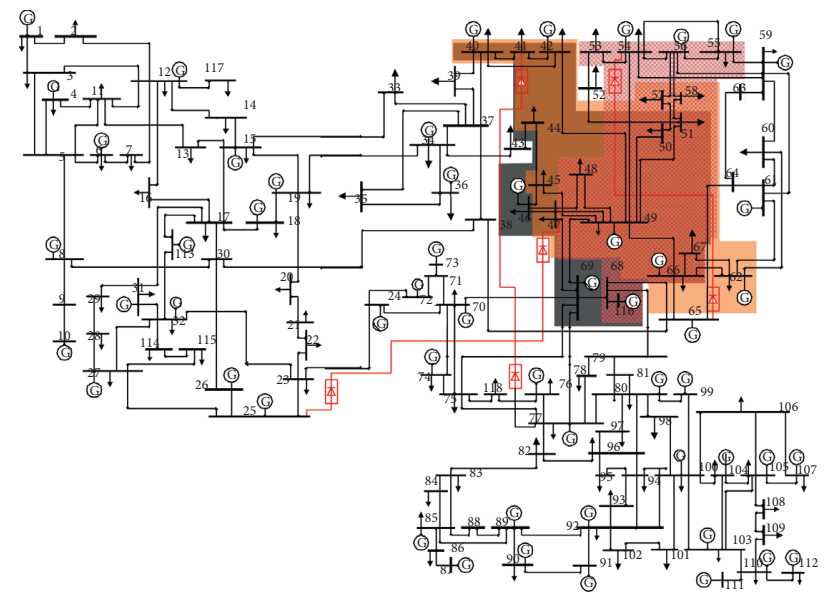

HVDC-1

(d)

FIgure 16: Critical failure impedance boundaries of the IEEE 118-bus test system. (a) Three-phase short-circuit fault boundary. (b) Single line-to-ground fault boundary. (c) Double line-to-ground fault boundary. (d) Line-to-line fault boundary.

\section{Conclusions}

This paper proposes a method to detect the CF of multiinfeed HVDC systems based on the critical failure impedance boundary. Using the criterion of the critical extinction angle, the proposed method can identify the critical failure impedance boundary where different kinds of faults are possible to cause the CF of the muti-infeed HVDC system.

Based on theoretical analysis and simulation results, it is concluded that (1) the critical failure impedance boundary increases with the decrease of the intensity of the AC system which is linked to the HVDC system. (2) When the impedance of the interconnected DC system remains constant, the change of system intensity affects the critical fault impedance boundary of the local HVDC subsystem significantly, while it casts little impact on other DC subsystems. (3) Compared with the actual power grid operation, the method presented in this paper is a programmatic calculation method, and the results are more rigorous. The calculated boundaries of commutation failures will be larger than the actual boundaries.

The proposed method using a critical failure impedance boundary to detect CF of a multi-infeed HVDC system can detect the AC system area where faults could cause the commutating failure of the DC system. It directly reflects the mutual effects between AC and DC systems on the system topology diagram and has the potential of being widely used in power system planning and operation.

\section{Nomenclature (abbreviations)}

HVDC: High-voltage direct-current

CF: Commutation failure

CB: $\quad$ Converter bus

MIIF: Multi-infeed interaction factor

VIF: Voltage interaction factor 


\section{Variables}

A: $\quad$ Commutation area

$k$ : Transformer tap ratio

$U_{L}$ : Voltage magnitude of converter buses

$\theta$ : $\quad$ Voltage angle of converter buses

$\gamma$ : Extinction angle of the converter

$I_{d}: \quad$ DC current

$\beta$ : Advance trigger angle of the converter

$Z$ : Impedance

$\Delta U:$ Voltage drop of AC buses

d: Zero-crossing phase shift of the commutating voltage

$U^{\prime}$ : Line-to-line voltage between two phases

$\dot{U}: \quad$ Voltage phasor

$\dot{I}$ : Current phasor.

\section{Data Availability}

The data used to support the findings of this study are available from the corresponding author upon reasonable request.

\section{Conflicts of Interest}

The authors declare that they have no conflicts of interest.

\section{Acknowledgments}

This paper is an improvement and update of the version of view in Reference [20], further complements the calculation and determination method of the extinction angle under unbalanced short-circuit fault, and carries out simulation verification on a larger scale power grid. The authors would like to thank the previous authors for their efforts and contributions in this field.

\section{References}

[1] S. Mirsaeidi, X. Dong, D. Tzelepis, D. M. Said, A. Dysko, and C. Booth, "A predictive control strategy for mitigation of commutation failure in LCC-based HVDC systems," IEEE Transactions on Power Electronics, vol. 34, no. 1, pp. 160-172, 2018.

[2] A. Zheng, C. Guo, P. Cui, W. Jiang, and C. Zhao, "Comparative study on small-signal stability of LCC-HVDC system with different control strategies at the inverter station," IEEE Access, vol. 7, pp. 34946-34953, 2019.

[3] L. Yang, Y. Li, G. Li, D. Zhao, and C. Chen, "Two-stage multiobjective OPF for AC/DC grids with VSC-HVDC: incorporating decisions analysis into optimization process," Energy, vol. 147, pp. 286-296, 2018.

[4] F. Wang, T. Q. Liu, and X. Y. Li, "Decreasing the frequency of HVDC commutation failures caused by harmonics," IET Power Electronics, vol. 10, no. 2, pp. 215-221, 2017.

[5] Y. Xue, X.-P. Zhang, and C. Yang, "Commutation failure elimination of LCC HVDC systems using thyristor-based controllable capacitors," IEEE Transactions on Power Delivery, vol. 33, no. 3, pp. 1448-1458, 2018.

[6] J. Wu, H. Li, G. Wang, and Y. Liang, "An improved travelingwave protection scheme for LCC-HVDC transmission lines," IEEE Transactions on Power Delivery, vol. 32, no. 1, pp. 106-116, 2017.
[7] C. H. Li, C. Liu, Z. A. Zhang, W. Yao, J. Y. Wen, and J. B. Wang, "Analysis of commutation failure in HVDC power transmission system considering prediction control of commutation failure and initial fault angle," Automation of Electric Power Systems, vol. 42, no. 3, pp. 56-76, 2018.

[8] E. Rahimi, A. M. Gole, J. B. Davies, I. T. Fernando, and K. L. Kent, "Commutation failure analysis in multi-infeed HVDC systems," IEEE Transactions on Power Delivery, vol. 26, no. 1, pp. 378-384, 2011.

[9] C. Guo, Y. Liu, C. Zhao, X. Wei, and W. Xu, "Power component fault detection method and improved current order limiter control for commutation failure mitigation in HVDC," IEEE Transactions on Power Delivery, vol. 30, no. 3, pp. 1585-1593, 2015.

[10] W. Yao, C. Liu, J. Fang, X. Ai, J. Wen, and S. Cheng, "Probabilistic analysis of commutation failure in LCC-HVDC system considering the CFPREV and the initial fault voltage angle," IEEE Transactions on Power Delivery, vol. 35, no. 2, pp. 715-724, 2020.

[11] H.-I. Son and H.-M. Kim, "An algorithm for effective mitigation of commutation failure in high-voltage direct-current systems," IEEE Transactions on Power Delivery, vol. 31, no. 4, pp. 1437-1446, 2016.

[12] H. Xiao, Y. Li, J. Zhu, and X. Duan, "Efficient approach to quantify commutation failure immunity levels in multi-infeed HVDC systems," IET Generation, Transmission \& Distribution, vol. 10, no. 4, pp. 1032-1038, 2016.

[13] Y. Xue, X.-P. Zhang, and C. Yang, "Elimination of commutation failures of LCC HVDC system with controllable capacitors," IEEE Transactions on Power Systems, vol. 31, no. 4, pp. 3289-3299, 2016.

[14] S. F. Huang, H. M. Shen, B. Fei, and O. Li, "Effect of commutation failure on the distance protection and the countermeasures," IET Generation, Transmission \& Distribution, vol. 9, no. 9, pp. 838-844, 2015.

[15] X. Ni, C. Zhao, C. Guo, H. Liu, and Y. Liu, "Enhanced line commutated converter with embedded fully controlled submodules to mitigate commutation failures in high voltage direct current systems," IET Power Electronics, vol. 9, no. 2, pp. 198-206, 2016.

[16] Y. Shao and Y. Tang, "Fast evaluation of commutation failure risk in multi-infeed HVDC systems," IEEE Transactions on Power Systems, vol. 33, no. 1, pp. 646-653, 2018.

[17] C. Liu, Y. Zhao, C. Wang, H. Li, and G. Li, "Superposition feature of the switching functions for the dynamic phasor model of the converters under commutation failure," IET Generation, Transmission \& Distribution, vol. 9, no. 12, pp. 1448-1454, 2015.

[18] J. He, Y. Tang, J. Zhang, Q. Guo, J. Yi, and G. Bu, "Fast calculation of power oscillation peak value on AC tie-line after HVDC commutation failure," IEEE Transactions on Power Systems, vol. 30, no. 4, pp. 2194-2195, 2015.

[19] A. Bagheri-Vandaei and S. Filizadeh, "Generalised extendedfrequency dynamic phasor model of LCC-HVDC systems for electromagnetic transient simulations," IET Generation, Transmission \& Distribution, vol. 12, no. 12, pp. 3061-3069, 2018.

[20] G. Li, S. Zhang, T. Jiang, H. Chen, and X. Li, "A method of detecting commutation failure in multi-infeed HVDC systems based on critical failure impedance boundary," in Proceedings of the 2017 IEEE Power \& Energy Society General Meeting, pp. 1-5, Chicago, IL, USA, July 2017. 